\title{
Dairy intensification in developing countries: effects of market quality on farm-level feeding and breeding practices
}

\author{
A. J. Duncan ${ }^{1 \dagger}{ }^{\dagger}$ N. Teufel ${ }^{2}$, K. Mekonnen ${ }^{1}$, V. K. Singh ${ }^{2}$, A. Bitew ${ }^{3}$ and B. Gebremedhin ${ }^{1}$ \\ ${ }^{1}$ International Livestock Research Institute, PO Box 5689, Addis Ababa, Ethiopia; ${ }^{2}$ International Livestock Research Institute, 904 Aggarwal Corporate Tower, \\ 23 Rajendra Place, New Delhi 110008, India; ${ }^{3}$ Amhara Regional Agricultural Reseach Institute, Andassa Livestock Research Centre, PO Box 27, Bahir Dar, Ethiopia
}

(Received 18 December 2012; Accepted 16 July 2013; First published online 8 October 2013)

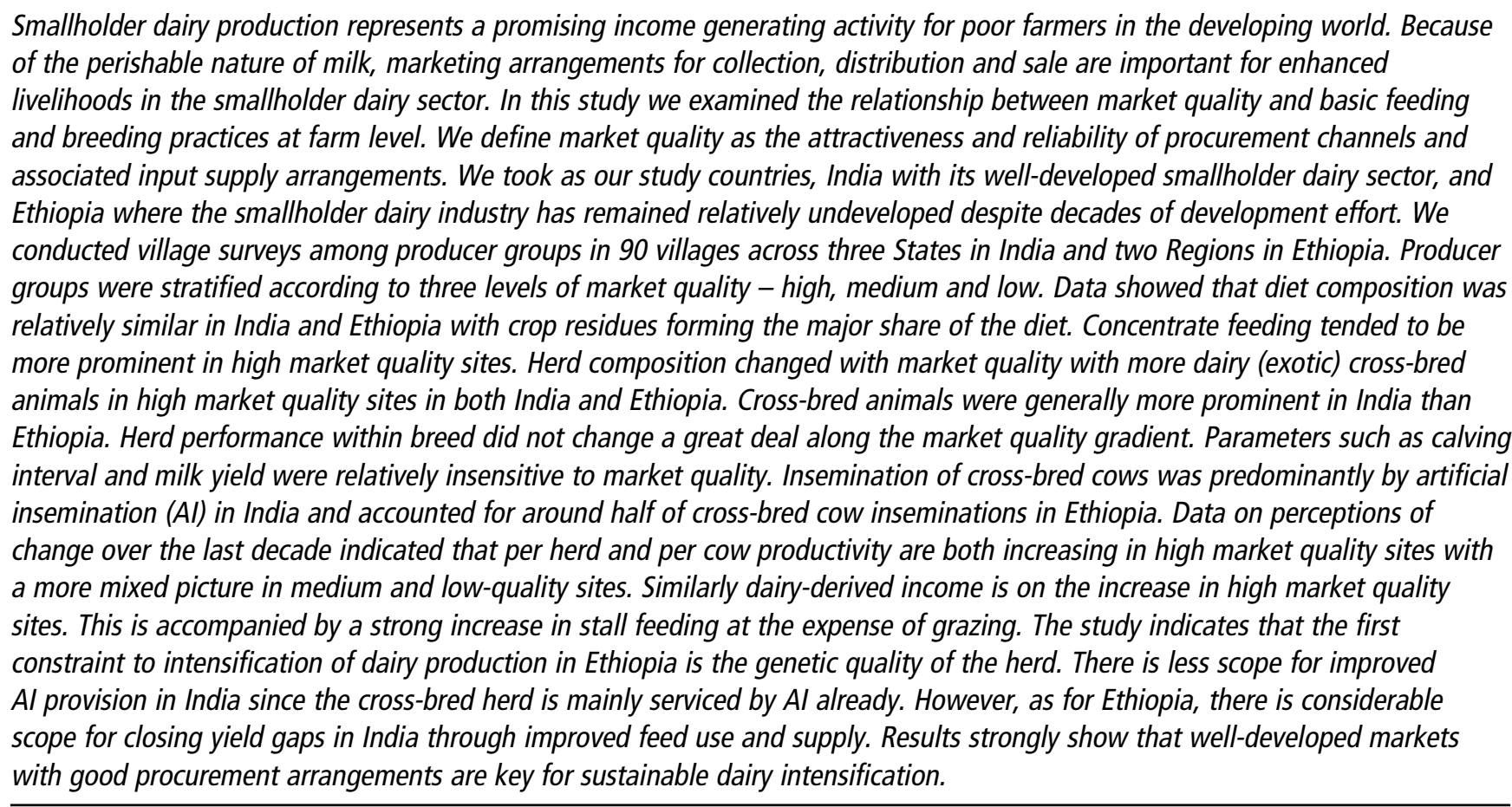

Keywords: dairy, intensification, market, India, Ethiopia

\section{Implications}

Dairy systems in developing countries continue to intensify in response to increasing human populations, declining land per head of population and increasing demands for animal source foods. Dairy production is a promising livelihood option for poor households. This study shows that dairy productivity per animal within breed is relatively stable across a gradient of market quality and that productivity improvements as market quality improves are mainly associated with greater proportions of genetically improved animals that are better fed. The quickest gains to dairy

\footnotetext{
${ }^{\dagger}$ E-mail: a.duncan@cgiar.org
}

production, especially in Ethiopia, would be through greater focus on improving the genetic merit of the dairy herd.

\section{Introduction}

Livestock systems in general are going through a period of unprecedented change (Seré et al., 2008) and dairy systems are no exception. The rapidly evolving scene is a response to a series of drivers including population growth and urbanisation, both of which contribute to increased demand for livestock products. We are now half-way through the so-called Livestock Revolution (Delgado et al., 1999) projected at the end of the 1990s and the predictions for increased 
demand for livestock products are being borne out in many parts of the world. Indeed, the demand for dairy products in some parts of the world has increased at a much faster rate than was predicted in the late 1990s (APHCAP et al., 2008); however, note work of Pica-Ciamarra and Otte (2011) for some caution on interpretation of evidence on increased demand for livestock products.

At the same time, poverty rates in rural areas of SubSaharan Africa and South Asia remain stubbornly high. Dairy development has often been identified as having an especially large potential for providing pathways out of poverty for poor rural livestock keepers, as livestock already form a considerable share of their assets and family labour is often not their greatest constraint (Staal, 2001). Increasing the productivity of the existing assets has often been regarded as the most sustainable approach to alleviating poverty (Bachmann, 2004). However, the noticeable increase in productivity of dairy production systems is not widespread. Significant efforts to enhance livestock (including dairy) production through productivity improving technologies across South Asia and especially in Sub-Saharan Africa have met with very limited success (Hall et al., 2007). Based on limited observations, our hypothesis is that at the household level, the main driver of intensification in dairy production appears to be the quality of available value chains. Quality ${ }^{1}$ in this context means the reliability and attractiveness of dairy procurement systems, which often includes the delivery of livestock-related services. In such instances, anecdotal evidence suggests that households seem to think it worthwhile to intensify dairy production by investing in better feeds and higher-yielding animals. We assume that market quality is generally exogenous to individual households and so can be taken as a given in household decision making.

Very little systematic research has been conducted on the comparative analysis of dairy systems based on market quality. The research reported here is, therefore, aimed to contribute to filling this gap. India and Ethiopia were selected as our study countries, since many poor livestock keepers are engaged in dairy production and a range of dairy system types exist in each country. The range of dairy system types encompasses at one extreme, zero grazed animals producing around $15 \mathrm{I}$ of milk per cow per day and being kept purely for milk production through to, at the other extreme, extensively grazed animals offered no supplementary feeding and producing $<1$ I per cow per day. The extent of dairy development varies considerably between these two countries, with India having a long history of developing various value chain components, most notably through the co-operative movement (Gautam et al., 2010), while in Ethiopia the development of

\footnotetext{
${ }^{1}$ Throughout the paper we use the term 'market quality' as shorthand for the reliability and attractiveness of milk procurement systems and the delivery of inputs such as improved feed, veterinary care, improved breeding services and credit. In many cases quality refers not just to physical infrastructure but to the institutional arrangements around milk procurement and input supply. In Ethiopia, despite the importance of the informal butter sector, market quality as we define it refers mainly to channels for liquid milk. However, our data includes both liquid milk and associated processed products.
}

market chains for fluid milk that extend beyond the very local, is relatively nascent (Ahmed et al., 2004). There are thus interesting comparisons to be made with a view to providing insights into where and how to target interventions aimed at enhancing dairy-derived incomes.

The research reported here involves a comparison of dairy systems in Ethiopia and India and specifically the effect of market quality on feeding and breeding practices. The study has a limited geographic scope and while the data provide a good overview, the absolute numbers should be interpreted with caution based on the relatively small geographic coverage of the study and the limited number of villages visited. However, the overall trends and the marked differences in feeding and breeding aspects of the dairy system in the two countries provide useful data that suggest possible intervention areas to improve dairy production by poor dairy farmers for enhanced income.

\section{Methods}

\section{Development of dairy system typology}

A typology of district/Woreda ${ }^{2}$-level dairy systems based on 'market quality' was developed early in the study. Three strata of market quality were defined as 'high', 'medium' and 'low' market quality. The specifics of these three categories differ by country but in general relate to the quality of procurement arrangements. In India, high market quality implies the presence of efficient dairy co-operatives, the activity of private sector dairy companies and perhaps evidence of interest in milk procurement from the supermarket sector. Medium market quality is characterised by conventional milk co-operatives whose functioning leaves room for improved efficiency and a large share of informal milk marketing. Low market quality districts are dominated by informal milk value chains with only minor contributions from dairy co-operatives and no activity by formal private sector dairy companies. In Ethiopia, high market quality implies the presence of dairy co-operatives with associated processing infrastructure and perhaps private processors who engage in milk procurement. Medium market quality denotes the presence of some organised milk procurement, usually through milk co-operatives but without milk processing facilities. Low market quality is characterised by the absence of milk marketing other than through informal exchange between households.

\section{Selection of case study sites}

Based on the above typology a series of case study sites was selected in India and Ethiopia (Supplementary Figure). Because of the markedly different geographical scale of India and Ethiopia attention was given to the equivalence of administrative units in the two countries. For the purposes of site selection, State (India) and Region (Ethiopia) were considered as equivalent; furthermore District (India) and

\footnotetext{
${ }^{2}$ Woreda is the main administrative district in Ethiopia and typically includes around 20000 households.
} 
Woreda (Ethiopia) were considered as equivalent. An expert consultation approach was adopted in India whereby acknowledged national experts were asked to score States based on variation in marketing quality, variation in production intensity, importance of dairy production and common production systems (e.g. irrigated rice-wheat; rain-fed cerealcotton). In Ethiopia selection of Regions was more qualitative and based on conversations with national experts; because of the scarcity of areas in which high market quality conditions exist, only two Regions were deemed to have sufficiently developed market quality conditions to be included in the study. In India, it was decided to focus on three States, namely Bihar, Punjab and Andhra Pradesh where dairy production is important and a variety of dairy marketing systems exist. The selected States represent the intensive, irrigated, semi-arid Northwest; the extensive, irrigated, sub-humid East; and the rain-fed South. In Ethiopia, Amhara Region and Oromiya Region were selected as the case study regions. Within each State/Region, six Districts/Woredas were selected for the survey with two representing high market quality, two medium market quality and two low market quality. In India, local experts classified all Districts in the selected States by market quality (as defined above). Subsequently, two districts were randomly selected from each milk marketing quality class by drawing lots. However, in one Indian State, Andhra Pradesh, the collected data contradicted the expert classification resulting in a reclassification of the six selected Districts. In Ethiopia, because of the paucity of secondary data on market quality, selection of Woredas according to market quality was left to collaborating scientists from the national research system who purposively selected Woredas based on their expert knowledge of market quality.

\section{Data collection}

A survey tool was devised to capture simple aggregate data on dairy feeding and breeding practices, dairy productivity and dairy-derived household impacts as well as on characteristics regarding milk marketing, service delivery and the institutional environment. Data were composed of farmer group recall data. Data were collected from six milk producer respondent groups per District/Woreda (two groups from three villages) yielding a data set including data from 180 respondent groups from 90 villages across India and Ethiopia (five States/Regions $x$ six Districts/Woredas $x$ three villages $\times$ two respondent groups). Respondents were groups of dairy producers and the subsequent unit of analysis was at the level of respondent group. Respondent groups were asked to give responses at village level, not just for the group. The average number of respondents per group in India was 9.0 (s.d. $=7.24$; females : total $=0.10$ ) while in Ethiopia it was 5.2 (s.d. $=1.47$; females : total $=0.21$ ). Selection of respondents was ad hoc but care was taken to include farmers from different wealth categories; this was achieved by estimating the average herd size in each village through enquiry among villagers and then selecting roughly equal numbers of respondents below and above the average threshold. Feeding data were disaggregated by season based on farmer recall. The seasons were named as 'dry', 'rainy' and 'winter' in both countries although because of varying agro-ecology, season definition differed by country and even within country. In Ethiopia the dry season was defined as occurring between February and June, the rainy season between July and September and the winter season between October and January. In India the definitions were broadly similar to Ethiopia but with some temporal variation due to the geographical dispersion of study States; the rainy season corresponds to the Kharif season, the winter season to the Rabi season and the dry season to the months following the Rabi season but before the Kharif season. Because of the markedly different stage of intensification in India and Ethiopia minor differences in survey questions were accommodated while ensuring that the collected data remained suitable for combined analysis and meaningful comparisons. The survey was implemented simultaneously in India and Ethiopia during March to May 2010.

\section{Data analysis}

Data were analysed using analysis of variance to test for the main effects of market quality, season and country and their respective interactions. When analysing the composition of stall-fed feeds, each of the three major feed components (dry fodder, green fodder, concentrate) was analysed separately since the proportions added to one meaning that the three ration composition variables were not independent. Herd composition data were analysed separately for each country since the presence of buffaloes in India but not in Ethiopia made direct comparison problematic. An additional analysis was therefore conducted considering the composition of the cattle herd only, characterised by the share of cross-bred cows. Data on calving interval, age at first calving, average daily milk yield and average annual milk yield were analysed separately for each country since the presence of buffaloes in India but not in Ethiopia again made direct comparisons problematic. Daily milk yield was based on farmer recall of average values while cows were lactating. Average annual milk yield was calculated according to the following formula: Average daily milk yield (I/day) $\times 30$ (day/month) $\times$ lactation length (months) $\times 12$ /intercalving period (months). Data on method of insemination were again proportional, adding to one, so analysis was conducted only on the reported percentage of animals per village inseminated by artificial insemination (AI), which is also the most important variable for characterising the technological development of breeding systems. Data on source and price of insemination services were highly variable and not amenable to analysis. The data are therefore presented as simple descriptive statistics.

\section{Results}

\section{Feeding strategies}

Feeding strategies are an important indicator of the intensity of production. According to respondents grazing was still an important source of nutrition for dairy animals comprising 
around half of the overall diet in Ethiopia and 20\% to $40 \%$ of the diet in India. There was some evidence for grazing accounting for a higher proportion of the diet in areas of low market quality, especially in India. Conversely, stall feeding tended to account for more of the overall diet as market quality increased. There was seasonal variation in the share of grazing especially in Ethiopia where grazing formed an important component of the diet during the 'winter' season when animals are allowed to graze. In general seasonal variation in diet composition was more pronounced in Ethiopia than in India. Stall feeding accounted for a higher proportion of the diet in India than in Ethiopia (Table 1).

The composition of the stall-fed diet was relatively similar in India and Ethiopia comprising dry fodder consisting mostly of crop residues (around 60\%), green fodder (around $25 \%$ ) and concentrate (around 15\%). The proportion of concentrate fed decreased with declining market quality in both countries as might be expected (Table 2). However, it should be kept in mind that the absolute amounts of stall-fed feeds, especially important with regard to concentrates, was lower in Ethiopia than in India, because of the greater contribution of grazing. As share of total feed, concentrates contributed $8 \%$ and $18 \%$ in Indian low and high market quality sites, respectively, while in Ethiopia the corresponding values are $7 \%$ and $14 \%$.

Table 1 Share of grazing by season and market quality

\begin{tabular}{llccc}
\hline \hline \multirow{2}{*}{ \% DM total feed } & \multicolumn{3}{c}{ Market } \\
\cline { 3 - 5 } Ethiopia & \multicolumn{1}{c}{ Season } & High & Medium & Low \\
& Dry & 24 & 22 & 45 \\
& Rainy & 36 & 45 & 39 \\
& Winter & 70 & 65 & 77 \\
India & Ethiopia mean & 44 & 44 & 53 \\
& Dry & 19 & 15 & 39 \\
& Rainy & 19 & 25 & 45 \\
& Winter & 20 & 17 & 45 \\
& India mean & 20 & 19 & 43 \\
\hline \hline
\end{tabular}

Statistical significance: country, $P<0.001$; market, $P<0.001$; season, $P<0.001$; country $\times$ market, $P=0.012$; country $\times$ season, $P<0.001$.

Table 2 Feed composition of stall fed feed

\begin{tabular}{llccr}
\hline \hline & & \multicolumn{3}{c}{ Market } \\
\cline { 3 - 5 } \% DM stall-fed feed & Feed type & High & Medium & Low \\
\hline Ethiopia & Dry fodder & 58 & 64 & 63 \\
& Green fodder & 17 & 25 & 28 \\
\multirow{2}{*}{ India } & Concentrate & 25 & 11 & 9 \\
& Dry fodder & 54 & 61 & 58 \\
& Green fodder & 24 & 23 & 29 \\
& Concentrate & 22 & 16 & 13
\end{tabular}

Statistical significance: dry fodder country, NS; market, NS; country $\times$ market, NS; green fodder country, NS; market, $P<0.05$; country $\times$ market, $P<0.001$; concentrate country, NS; market, NS; country $\times$ market, NS.

\section{Breed composition}

Breed composition also differed by market quality. The proportion of cross-bred animals declined with declining market quality in both countries, while the share of indigenous cows decreased. However, a trend for the share of buffaloes over the three market quality categories could not be established (Table 3). The proportion of indigenous animals was generally higher in Ethiopia than in India comprising nearly $90 \%$ of the cows in areas of low market quality (Supplementary Table 1).

\section{Performance}

Herd performance data showed that, as expected, cross-bred cows performed better than indigenous cows. In addition, in general, Indian herds showed higher performance than Ethiopian herds. The effects of market quality within breed were relatively minor in magnitude.

For example, overall average calving intervals for indigenous and cross-bred cows in Ethiopia were 22.5 and 15.6 months, respectively. The corresponding figures for India were 17.1 and 13.8 months with 17.9 months being recorded for buffaloes. Market quality appeared to have no systematic effect on calving interval despite some significant differences (Table 4).

For age at first calving a similar pattern was observed. Mean values for age at first calving in Ethiopia were 49.8 and 33.4 months for indigenous and cross-bred cows, respectively. The corresponding figures for India were 41.4 and 30.2 months; the value for buffaloes was 44.0 months (Supplementary Table 2). While market quality had no influence on age at first calving in Ethiopia, heifer fertility increased significantly with market quality in India with all three animal types showing decreased age at first calving with improved marketing. The difference was greatest between medium and high marketing quality sites.

For average daily milk yields, collected as recall data from respondents, there were the expected large differences between indigenous and cross-bred cows but the proportional differences were more pronounced in Ethiopia than in India. Average values in Ethiopia were 1.7 and $6.6 \mathrm{I}$ per cow per day for indigenous and cross-bred cows, respectively. In India the corresponding yields were 4.2 and 9.6 I per cow per day. Buffaloes were reported to be yielding $5.5 \mathrm{I}$ of milk

Table 3 Share of animal type within herd by market quality

\begin{tabular}{llrrr}
\hline \hline \multirow{2}{*}{$\begin{array}{l}\text { Animals of total } \\
\text { adult females }\end{array}$} & Animal type & High & Medium & Low \\
\cline { 3 - 5 } Ethiopia & Indigenous cow & 42 & 72 & 89 \\
& Cross-bred cow & 58 & 28 & 12 \\
\multirow{3}{*}{ India } & Buffalo & 0 & 0 & 0 \\
& Indigenous cow & 9 & 15 & 31 \\
& Cross-bred cow & 29 & 20 & 10 \\
& Buffalo & 62 & 65 & 59 \\
\hline \hline
\end{tabular}

Statistical significance: animal type $\times$ market for Ethiopia, $P<0.001$; animal type $\times$ market for India, $P<0.001$. 
Duncan, Teufel, Mekonnen, Singh, Bitew and Gebremedhin

Table 4 Effect of market quality on calving interval and average annual milk yield

\begin{tabular}{|c|c|c|c|c|}
\hline & \multirow[b]{2}{*}{ Animal type } & \multicolumn{3}{|c|}{ Market } \\
\hline & & High & Medium & Low \\
\hline \multicolumn{5}{|c|}{ Calving interval (months) } \\
\hline \multirow[t]{3}{*}{ Ethiopia } & Indigenous cow & 21.2 & 25.0 & 21.2 \\
\hline & Cross-bred cow & 15.1 & 16.6 & 15.1 \\
\hline & Ethiopia mean & 18.1 & 20.8 & 18.5 \\
\hline \multirow[t]{4}{*}{ India } & Indigenous cow & 16.1 & 17.9 & 17.4 \\
\hline & Cross-bred cow & 13.4 & 14.3 & 13.6 \\
\hline & Buffalo & 17.7 & 17.3 & 18.6 \\
\hline & India mean & 15.9 & 16.6 & 16.9 \\
\hline \multicolumn{5}{|c|}{ Average annual milk yield (litres) } \\
\hline \multirow[t]{3}{*}{ Ethiopia } & Indigenous cow & 381 & 189 & 258 \\
\hline & Cross-bred cow & 2017 & 1161 & 1500 \\
\hline & Ethiopia mean & 1199 & 675 & 874 \\
\hline \multirow[t]{4}{*}{ India } & Indigenous cow & 818 & 649 & 660 \\
\hline & Cross-bred cow & 2670 & 2190 & 2272 \\
\hline & Buffalo & 1166 & 1033 & 1035 \\
\hline & India mean & 1552 & 1290 & 1322 \\
\hline
\end{tabular}

Statistical significance: calving interval Ethiopia - market, $P<0.001$; animal type, $P<0.001$; market $\times$ animal type, $P<0.05$; calving interval India: market, $P<0.01$; animal type, $P<0.001$; market $\times$ animal type, NS; annual milk yield Ethiopia: market, $P<0.01$; animal type, $P<0.001$; market $\times$ animal type, NS; annual milk yield India: market, NS; animal type, $P<0.001$; market $\times$ animal type, NS.

per cow per day, however with double the fat content of cows' milk. There was no effect of market quality on daily milk yield in India within breed, while there was a minor effect in Ethiopia with cows in high market quality sites yielding more than in medium and low-quality sites (Supplementary Table 2).

Average annual milk yield (calculated from average daily milk yield, calving interval and lactation length) showed a similar pattern to that of daily milk yield. However, both animal type and market effects were detected for both countries for this variable. Cross-bred cows in Ethiopia yield more than five times as much milk as indigenous cows (1556 v. 276 l/year). In India cross-bred cows yielded a little over three times as much milk as indigenous cows (2384 v. $708 \mathrm{l} /$ year) with buffaloes showing an average annual milk yield of $1078 \mathrm{l} /$ year. Comparing market quality classes, average annual milk yield also increased moving from medium to high-quality sites (Table 4).

\section{Breeding practices}

The survey data indicated that artificial insemination was the dominant means of inseminating cross-bred cows in India regardless of market quality (over $90 \%$ for all market quality classes). Even among indigenous cows a reasonable proportion was inseminated artificially (overall average $43 \%$ ). In Ethiopia, a similar pattern was observed except at a lower level; the corresponding percentages for Al among crossbred and indigenous cows were $59 \%$ and $12 \%$ respectively. In general, the use of Al among indigenous cows (and buffaloes in India) decreased with declining market quality in both Ethiopia and India. Among cross-bred cows, the extent of Al use was insensitive to market quality. In India this was probably due to saturation effects while in Ethiopia, the
Table 5 Types of insemination service by market quality (percentage of animals inseminated by different methods)

\begin{tabular}{lccr}
\hline \hline & \multicolumn{3}{c}{ Market } \\
\cline { 2 - 4 } & High & Medium & Low \\
\hline Ethiopia & & & \\
$\quad$ Indigenous cow & 18.4 & 7.5 & 9.1 \\
$\quad$ Crossbreed cow & 56.7 & 51.3 & 72.6 \\
$\quad$ Ethiopia mean & 38.0 & 29.4 & 36.3 \\
India & & & \\
$\quad$ Indigenous cow & 61.7 & 37.7 & 28.2 \\
Crossbreed cow & 94.0 & 94.6 & 91.4 \\
Buffalo & 53.0 & 30.9 & 27.1 \\
$\quad$ India mean & 68.3 & 52.6 & 44.4 \\
\hline \hline
\end{tabular}

Statistical significance: country, $P<0.001$; market, $P<0.001$; country $\times$ market $P<0.05$; animal type, $P<0.001$; country $\times$ animal type, NS.

presence of development projects in low market quality sites may have created some anomalies in Al use (Table 5).

Improved bulls hardly featured in the Indian sites but were a prominent means of insemination in Ethiopia, particularly in high market quality sites, where they provided nearly half of all inseminations. On the other hand, service by indigenous bulls was dominant among indigenous cows in Ethiopia low market quality sites. In India cross-bred cows were predominantly inseminated by Al. Roughly one-third to two-thirds of indigenous cows were also inseminated by Al especially in high market quality sites (Supplementary Table 3).

In Ethiopia, results indicate that Al was almost exclusively provided by government suppliers (the Woreda agriculture offices) regardless of market quality, whereas in India a more 

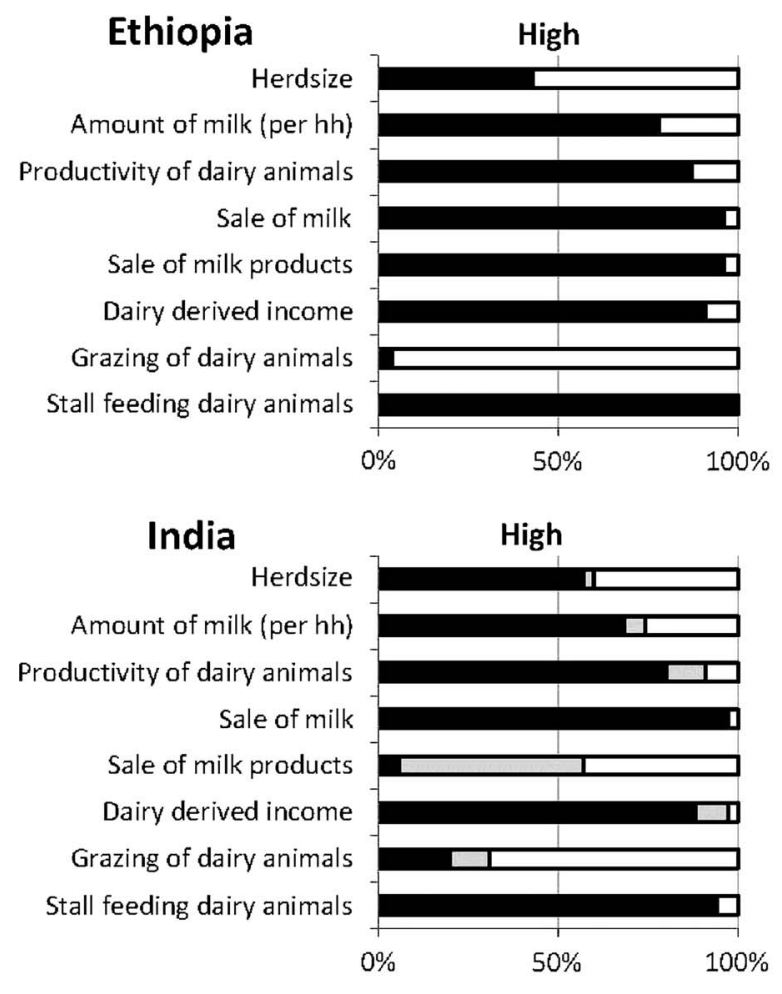
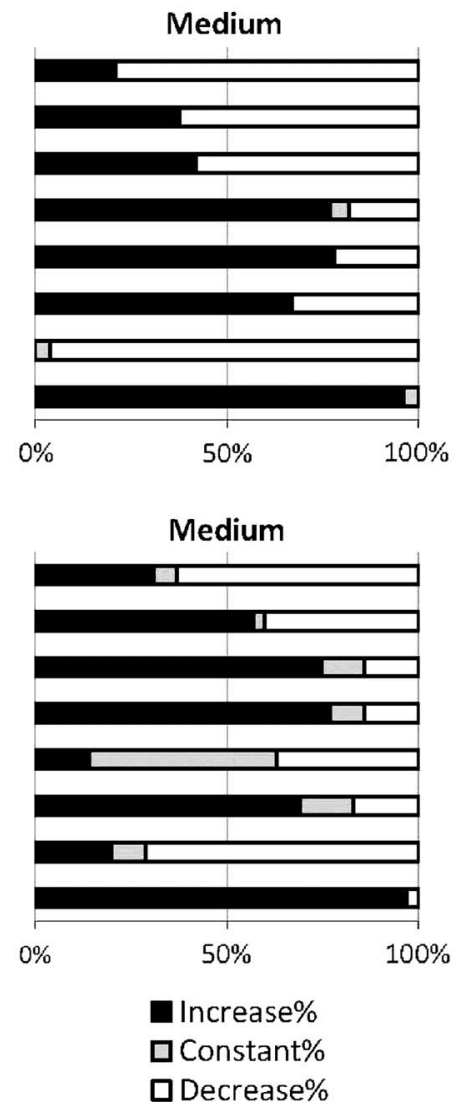

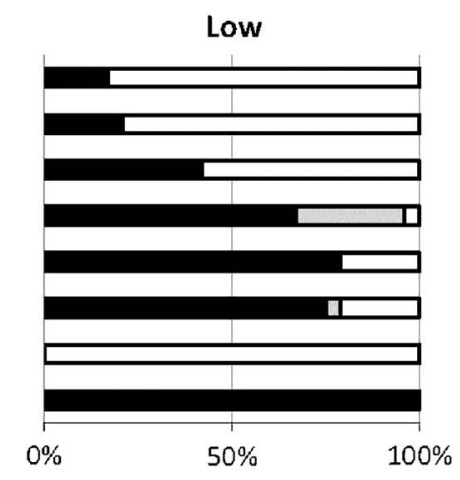

Low

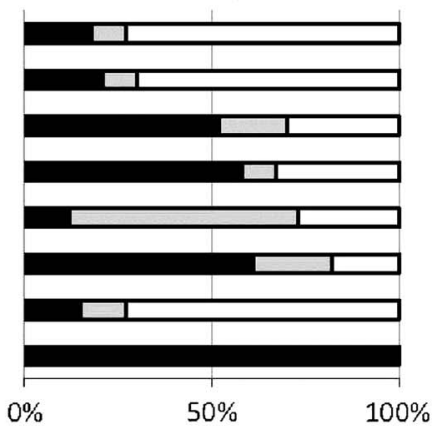

Figure 1 Trends in dairy development over the past 10 years (percentage of responses) from the perspective of milk producers.

mixed picture emerged. Here, government suppliers were also important but we found evidence that private Al suppliers were providing a growing share of Al services, particularly in high and medium market quality sites (Supplementary Table 4).

The charges for insemination services were generally low relative to true costs in Ethiopia at around 0.30 USD per attempt. In India, charges were higher at around 2 USD per insemination. While the price of government Al service decreased with market quality $(0.31$ v. 0.25 USD per service in high and low market quality sites in Ethiopia; 1.76 v. 1.38 USD per service in high and low market quality sites in India), private suppliers were asking for double the charge in low market quality sites compared with high market quality sites (4.07 v. 1.87 USD per service in India in low and high market quality sites; no private suppliers in high market quality sites in Ethiopia) indicating the costs of poorer market access (Supplementary Table 4).

\section{Trends in dairy development over the past 10 years}

As part of this study, milk producers were asked about their perception of trends in dairy development over the past decade to provide an overall picture on how things are changing and what can be expected in coming years. We should emphasise that these are perception data and should be treated with caution. When asked about changing herd sizes, respondents in medium and low market quality sites in both India and Ethiopia indicated that herd sizes are declining. In high market quality sites there was a more mixed picture suggesting fairly static overall herd size in these sites. In contrast, the amount of milk produced per household was reported to have increased in high-quality sites in both India and Ethiopia indicating improved productivity per cow and this was borne out by responses to questions about changing per cow productivity over the past decade. This pattern was not sustained in medium and low market quality sites in Ethiopia with respondents reporting an overall decline in the amount of milk produced per household in these sites. When asked about productivity respondents reported a mixed picture suggesting fairly static productivity. A similar pattern was found in Indian sites except that respondents reported increasing productivity in medium market quality sites (Figure 1).

Sales of milk by producers were reported to have increased in all sites and the effect was particularly strong in high market quality sites, as expected. The patterns in Ethiopia and India were similar. Sale of milk products was also reported to have increased in Ethiopia, especially in high market quality sites but this contrasted with data from India which showed a decline in sale of milk products especially in high market quality sites. Dairy-derived income was reported to have increased in all sites in both India and Ethiopia and the effect was particularly strong in the high market quality sites (Figure 1).

Finally, respondents were asked about changes in feeding practices and some strong trends emerged. Respondents reported an increase in stall feeding and a decrease in grazing across all levels of market quality in both India and Ethiopia. 
The decline of grazing was less pronounced for India with some producers reporting an increase in grazing (Figure 1).

\section{Discussion}

The current study examined the influence of market quality of dairy production in India and Ethiopia on production intensity, characterised mainly by farm-level feeding and breeding practices. The market quality gradient we studied in both India and Ethiopia provides a snapshot of how the systems are developing in the two countries and could provide pointers to the future. Systematic research on dairy systems in Ethiopia is scarce and there are few widely available studies with good primary data on farm-level practices. Data are available on reproductive performance of cross-bred and indigenous dairy cows but mainly at station level or in very limited areas that have been subject to favourable dairy development initiatives (Haile-Mariam et al., 1993; Shiferaw et al., 2003; Demeke et al., 2004; Lobago et al., 2007). Data on farm level feeding practices is scarce although some relatively generic adoption data are available (Mekonnen et al., 2010). Many development projects have, over the years, focused their activities on the Addis Ababa milkshed and there are few studies which take a wider geographical perspective (see Yigrem et al., 2008). Data on dairy production in India are, of course, more widespread (Gupta, 1981; Patil and Udo, 1997; Staal et al., 2008) but comparisons with Africa are less common.

In terms of livestock feeding, results show that market quality stimulates stall feeding and the use of concentrates. The data indicate an increase in stall feeding at the expense of grazing as systems intensify. This is also borne out by the trends section and is in line with what would be expected as systems intensify (Bebe and Udo, 2008). The share of grazing as a percentage of the total diet was generally higher in Ethiopia reflecting the less intensive nature of dairy production. The overall composition of stall-fed material was remarkably similar in Ethiopia and India with dry fodder (mainly crop residues) accounting for the major share of the diet with green fodder also contributing a significant proportion. The dominance of crop residue in livestock diets in Ethiopia is in agreement with broad estimates in other studies (Bediye and Feyissa, 2007). Concentrates were also important especially in the more intensive sites. However, the data do not allow any conclusions to be drawn on the quality of these concentrates. Studies in Uganda show that commercial dairy concentrates are highly variable in quality and often show nutritive values far below those stated by sellers (Lukuyu et al., 2012).

On the breeding side, results show that market quality is associated with a higher proportion of improved cows. This suggests that the major gains in production in high market quality sites are associated with increased numbers of crossbred cows being fed the better feed they need to keep producing. Moreover, improved breeding techniques are also generally associated with higher market quality. While $\mathrm{Al}$ is predominantly used in cross-bred cows in both countries irrespective of market quality, market quality stimulates the use of Al on indigenous cows, thereby increasing the share of cross-bred cows. In Ethiopia where the Al service is underdeveloped, market quality stimulates the use of improved bulls. Private Al services, generally more responsive to farmer demands, are more prevalent in higher and medium market quality sites in India, indicating the importance of private dairy services as systems intensify. In Ethiopia private Al provision is minimal. Previous studies have pointed to the dysfunctional nature of the Ethiopian Al system (Gebremedhin, 2008). Costs of Al services generally reduce as market quality increases indicating that improved market quality helps to reduce the cost of $\mathrm{Al}$ service delivery and therefore where market quality is low, that access to Al services will continue to be dependent on public subsidised services.

On the husbandry side we found that the improved feeding regimes at the high-quality sites were not closely reflected in the expected positive effects on daily milk yield moving up the market quality gradient. Reproductive parameters such as calving intervals and age at first calving show only minor improvements in high market quality sites. While daily milk yields per animal do not improve as systems intensify in India, we do find small productivity increases in the Ethiopian high market quality sites. At this stage, it is difficult to identify causes for this lack of strong productivity increases. Part of the increased concentrate consumption can be explained by the replacement of indigenous cows with cross-bred cows, especially in Ethiopia, where concentrate differences are smaller and the breed replacement stronger. However, in India only $20 \%$ of the dairy herd is affected by this change; buffaloes continuously represent over $50 \%$ in all quality sites. The reasons for this apparent disconnect between inputs and outputs need further investigation. First, data issues could be responsible. While breeding practices and the proportion of cross-bred and indigenous cows in the herd are easy to recall, average milk yield may not be an ideal variable for group interviews. Similarly, considering diet composition for the overall herd may mask links between feed inputs and milk outputs for individual animals. Second, the quality of concentrates replacing grazing and fodder is not assessed. In many cases, cereal milling products are classified as concentrates despite their relatively low nutrient density. Third, differences in feeding may have led to varying milk composition and this was not recorded.

Despite the limited effect on daily milk yield, the calculated average annual milk yields are higher in high-quality sites, mainly because of the combined effects of reducing the duration of unproductive periods through a combination of reduced calving interval and a shorter dry period. Most of the farm-level productivity increases linked to milk market quality appear to be based on improving genetic material rather than to changes in management. From a farmer's point of view this seems rational as moving from indigenous to cross-bred cows brings considerable benefits for milk yield with only a moderate investment in $\mathrm{Al}$, as long as sufficient fodder at reasonable quality levels is available. On the other hand, increasing milk yield through improved nutrition alone 
requires specialist knowledge of nutritional management of cows which is often lacking. Our data on calving interval and age at first calving are broadly in line with those found in other studies (Lobago et al., 2007; Shiferaw et al., 2003) although other studies have not looked at variation along an intensification gradient.

The data presented in this study are not, it should be stated, representative of national data. States/Regions were specifically selected for variation and importance in dairy production, while an equal number of Districts/Woredas were selected per quality class in each State/Region, irrespective of the distribution of these classes. Indeed, in Ethiopia, the data seems to be skewed in favour of more intensive producers. The data are useful, however, especially in terms of seeing the overall effect of market quality, trends within country and for cross-country comparison purposes.

\section{Conclusions}

In terms of scope for improvement, our evidence suggests that the quickest gains in Ethiopia are to be gained by radically improving the $\mathrm{Al}$ service in order to upgrade the genetic stock of the herd. Al still forms a minor share of overall breeding methods in Ethiopia and this reflects the dysfunctional nature of the Al system in the country. If lessons are to be learned from India and as previous experiences in Ethiopia show (IPMS, 2011), then there could be scope for passing responsibility for Al to co-operatives, or improving the enabling environment for private Al provision. In India, there is less potential for increasing dairy productivity through improved Al provision. The majority of cross-breds are already serviced by Al and efficiency is reasonable. However, the prospect of improving the genetic potential of buffaloes, the main dairy animal in the study sites, through Al is more limited compared with cattle, as high-yielding exotic breeds do not exist. Nevertheless, improvements in breeding programmes offer great long-term benefits but require considerable public and private investments.

On the feeding side our data emphasise the importance of crop residues in the feeding of dairy animals in both India and Ethiopia and in both countries there must be considerable scope for improving this low-quality material through feed interventions. In both countries there is a trend towards increased feeding of concentrate feeds. To support this change in feeding pattern interventions should focus on facilitating supply of concentrate feeds by support to the small agribusiness sector and improving market links between feed suppliers and smallholder dairy producers.

A major conclusion of this analysis relates to the role of dairy market development as a pull factor for intensifying dairy production. Farmers report that dairy production in the low and medium market quality sites are unstable or declining. Trend data show that overall milk produced at household level and herd size have been declining over the past 10 years. These results imply that sustainable intensification of dairy systems require well-developed markets with processing infrastructure, the policy implication being that governments need to provide appropriate incentives to cooperatives or the private sector to invest in marketing and processing infrastructure.

In summary, this cross-country comparison of feeding and breeding practices across a gradient of market quality in two very different countries shows that smallholder dairy systems are in considerable flux. In Ethiopia, there seems considerable scope for improving the genetic quality of the herd through support to private or co-operative-based Al services. This would need to be accompanied by improvements to feed supply notably by making more efficient use of crop residues and by facilitating access to high-quality concentrate feeds. In India, per cow performance relatively stable across the intensification gradient. However, only in high-quality market areas does dairy production appear to be growing. In all Indian sites there is considerable potential to reduce yield gaps through improved feeding, especially better use of concentrate feed. The importance of well-developed marketing systems with processing infrastructure stands out in both countries.

\section{Acknowledgements}

This work was funded through a grant from the OPEC Fund for International Development. The authors thank Zerihun Tadesse for assistance with statistical analysis.

\section{Supplementary Material}

To view supplementary material for this article, please visit http://dx.doi.org/10.1017/S1751731113001602.

\section{References}

Ahmed MAM, Ehui S and Assefa Y 2004. Dairy development in Ethiopia, vol. 123. IPFRI-EPT, Washington, DC, USA.

APHCAP, CFC and FAO 2008. Strategy and investment plan for smallholder dairy development in Asia, 2008/10. FAO, Bangkok, Thailand.

Bachmann F 2004. Livelihood and livestock: lessons from Swiss livestock and dairy development programmes in India and Tanzania, vol. 4. Intercooperation, Berne, Switzerland.

Bebe BO, Udo HMJ and Thorpe W 2008. Characteristics of feeding and breeding practices for intensification of smallholder dairy systems in the Kenya highlands. Livestock Research for Rural Development, volume 20, article \#23. Retrieved September 21, 2013, from http://www.Irrd.org//rrd20/2/bebe20023.htm

Bediye $S$ and Feyissa F 2007. The status of animal feeds and nutrition in the West Shewa Zone of Oromiya, Ethiopia. In Indigenous tree and shrub species for environmental protection and agricultural productivity. In Proceedings of the Workshop 'Indigenous Tree and Shrub Species for Environmental Protection and Agricultural Productivity', November 7-9, 2006 - Holetta Agricultural Research Centre (HARC), Ethiopia (ed. M Kindu, B Glatzel and B Habermann), Commission for Development Studies at the Austrian Academy of Sciences, VOEAW, Vienna.

Delgado C, Rosegrant M, Steinfeld H, Ehui S and Courbois C 1999. Livestock to 2020: the next food revolution, vol. 28. International Food Policy Research Institute, Washington, DC, USA.

Demeke S, Neser FWC and Schoeman SJ 2004. Estimates of genetic parameters for Boran, Friesian, and crosses of Friesian and Jersey with the Boran cattle in the tropical highlands of Ethiopia: milk production traits and cow weight. Journal of Animal Breeding and Genetics 121, 163-175.

Gautam, Dalal RS and Pathak V 2010. Indian dairy sector: time to revisit operation flood. Livestock Science 127, 164-175.

Gebremedhin DG 2008. Assessment of problems/constraints associated with artificial insemination service in Ethiopia. MSc Thesis; Addis Ababa University. 


\section{Duncan, Teufel, Mekonnen, Singh, Bitew and Gebremedhin}

Gupta BN 1981. Dairy cattle feed resources and feeding practices in the NorthEastern States. National Dairy Research Institute, Karnal.

Haile-Mariam M, Banjaw K, Gebre-Meskel T and Ketema H 1993. Productivity of Boran cattle and their Friesian crosses at Abernossa Ranch, Rift Valley of Ethiopia. I. Reproductive performance and pre-weaning mortality. Tropical Animal Health and Production 25, 239-248.

Hall A, Sulaiman R and Bezkorowajnyj P 2007. Reframing technical change: livestock fodder scarcity revisited as innovation capacity scarcity. CGIAR Systemwide Livestock Programme; Addis Ababa, pp. 1-52.

IPMS 2011. Dairy. A synthesis of IPMS value-chain development experiences. Improving Productivity and Market Success (IPMS) of Ethiopian Farmers Project. Commodity Summaries. IPMS, Addis Ababa.

Lobago F, Bekana M, Gustafsson H and Kindahl H 2007. Longitudinal observation on reproductive and lactation performances of smallholder crossbred dairy cattle in Fitche, Oromia Region, central Ethiopia. Tropical Animal Health and Production 39, 395-403.

Lukuyu B, Baker D, Baltenweck I, Poole J, Kabi F, Katongole G, Byarugaba A, Kugonza J and Wabwire R 2012. The concentrate feeds supply chain in Uganda: emerging trends and implications on quality and access to smallholder farmers and chain efficiency. East Africa Dairy Development Project, Nairobi.

Mekonnen H, Dehninet G and Kelay B 2010. Dairy technology adoption in smallholder farms in Dejen district, Ethiopia. Tropical Animal Health and Production 42, 209-216.
Patil BR and Udo HMJ 1997. The impact of crossbred cows in mixed farming systems in Gujarat, India: milk production and feeding practices. Asian Australisian Journal of Animal Sciences 10, 253-259.

Pica-Ciamarra U and Otte J 2011. The 'Livestock Revolution': rhetoric and reality. Outlook on Agriculture 40, 7-19.

Seré C, van der Zijpp AJ, Persley G and Rege JEO 2008. Dynamics of livestock production systems, drivers of change and prospects for animal genetic resources. Animal Genetic Resources Information 42, 3-27.

Shiferaw Y, Tenhagen BA, Bekana M and Kassa T 2003. Reproductive performance of crossbred dairy cows in different production systems in the central highlands of Ethiopia. Tropical Animal Health and Production 35, 551-561.

Staal SJ 2001. The competitiveness of smallholder dairy production: evidence from Sub-Saharan Africa, Asia, and Latin America. South-South Workshop on Smallholder Dairy Production and Marketing - Constraints and Opportunities, 13 to 16 March 2000, Anand, Gujarat.

Staal SJ, Pratt AN and Jabbar M 2008. Dairy development for the resource poor, Part 3: Pakistan and India dairy development case studies, pp. 44-53. FAO, Rome, Italy.

Yigrem S, Beyene F, Tegegne A and Gebremedhin B 2008. Dairy production, processing and marketing systems of Shashamene-Dilla area, South Ethiopia. IPMS (Improving Productivity and Market Success) of Ethiopian Farmers Project Working Paper 9. 